\title{
Definitions and Developmental Processes in Research on Infant Morality
}

\author{
Commentary on Tafreshi, Thompson, and Racine
}

Audun Dahl

University of California, Berkeley, Calif., USA

\author{
Key Words \\ Infancy · Looking-time methodology · Moral development
}

\begin{abstract}
Say what you choose, so long as it does not prevent you from seeing the facts. (And when you see them there is a good deal that you will not say.)

Wittgenstein [1953, p. 37]
\end{abstract}

Key terms used by researchers on early moral development often exist in everyday language. Consequently, when researchers say "innate," "morality," or "antisocial," these terms are subject to interpretations that may stray from the intended meaning. While "innate" probably means "typically present at birth" for most people, some researchers use it to mean "[not] gotten into the head by means of the extraction of information from the environment" [Bloom, 2012, p. 72]. In their target article, Tafreshi, Thompson, and Racine [this issue] argue that (1) researchers are responsible for using terms in a way consistent with the colloquial usage of these terms and (2) researchers using looking-time measures to support claims about infants' early sociomoral abilities do not live up to this responsibility. Tafreshi and her colleagues focus their critique on two lines of looking-time research on false belief understanding [e.g. Onishi \& Baillargeon, 2005] and infant sociomoral evaluations [e.g. Hamlin \& Wynn, 2011; Hamlin, Wynn, \& Bloom, 2007].

This is not the first time that researchers have cautioned against attributing advanced or adult-like abilities in infants [Allen \& Bickhard, 2013; Aslin, 2007; Fischer \& Bidell, 1991; Haith, 1998; Kagan, 2008]. However, such a cautionary note seems particularly appropriate in reference to research on infant morality based on preferential looking and reaching paradigms. First, the indices used (looking and reaching) have limited face validity - i.e., they would not appear to the layperson as measuring

\begin{tabular}{ll}
\hline KARGER & $\odot$ 2014 S. Karger AG, Basel \\
E-Mail karger@karger.com & $0018-716 \mathrm{X} / 14 / 0574-0241 \$ 39.50 / 0$ \\
www.karger.com/hde &
\end{tabular}

Audun Dahl

Institute of Human Development

University of California

Berkeley, CA 94720-1690 (USA)

E-Maildahl@berkeley.edu 
the construct they purport to measure [Nevo, 1985; this is not to say that the indices necessarily lack other forms of validity]. Second, the construct under investigation (morality) is notoriously subject to varying interpretations among researchers and nonresearchers (see below).

While I thus agree with one central tenet of the target article, I am less convinced that the conceptual analysis proposed by Tafreshi and her colleagues will bring us closer to understanding early moral or social development. Their solution to the problem of using everyday concepts in scientific discourse is to force researchers to follow common usage of terms: "If Hamlin and colleagues wish to apply an everyday sense of preference to the interpretation of looking time studies, it is worth considering how adults go about speaking about preferences" [Tafreshi et al., this issue]. I imagine that Hamlin and her colleagues [e.g. Hamlin et al., 2007] would simply respond that they do not wish to use the word "preference" in its everyday sense. Technical usage of everyday terms exists in most areas of research without seemingly causing much confusion. For instance, the word "resistance" is used in electronics without leading anyone to think that carbon resistors endorse a particular political ideology. (Not all proponents of conceptual analysis insist that scientific and everyday usage of terms coincide [Machado \& Silva, 2007].) I am also not convinced that a conceptual analysis by itself can do much to resolve "enduring disagreement" about major issues, as proposed by Tafreshi and her colleagues. Rather, conceptual clarity serves to make researchers see theoretical differences more clearly and then determine which studies are needed to test the conflicting views.

This commentary builds on the target article by discussing an alternative, yet critical, approach to the attribution of morally relevant capacities to infants. I argue for the need to provide clearer definitions of key terms (whether or not those definitions align with nonscientific definitions), for caution before attributing complex abilities based on a limited set of dependent measures, and for consideration of developmental processes that precede and succeed the abilities in question.

\section{Two Key Terms: Morality and Innateness}

The starting point for any research inquiry is the posing of a question, for instance, “Do infants possess an innate moral sense?" In order to know how to answer that question, it is necessary to know what those words mean. This is not to say that researchers must adopt the definitions from everyday language use or from the Oxford English Dictionary (contrary to the view of Tafreshi and her colleagues, and also to that of Greene [2007], who argues that those who study moral psychology do not need to define the realm of morality). However, if the researcher engaged in the inquiry does not state what the words "morality" or "innateness" refer to in the question posed, there would be no way of knowing what kind of evidence is needed to answer the question.

Psychologists have defined morality in a variety of ways. Each of these definitions is associated with certain theoretical assumptions. Some have defined morality as the capacity to follow virtually any type of norm endorsed in a society [Haidt, 2008; Kochanska \& Aksan, 2006; Skinner, 1971]. These researchers have typically proposed, implicitly or explicitly, that the processes leading to the acquisition of norms is relatively independent of the content of the norm. Others have defined morality as entailing substantive issues such as others' rights and welfare, justice, or fairness [Gray, 
Young, \& Waytz, 2012; Turiel, 1983a, 1983b, 2014]. These definitions are often associated with the idea that the interactions through which children develop moral concerns differ from the interactions through which children acquire concerns with social conventions or other norms [for a review, see Smetana, 2013].

Many nativist approaches to morality have endorsed a broad definition of a moral sense as the "tendency to see certain actions and individuals as right, good, and deserving of reward, and others as wrong, bad, and deserving of punishment" [Hamlin, 2013, p. 186; see also Wynn \& Bloom, 2014]. This moral sense is argued to be innate (at least partly). The definition raises two noteworthy questions. The first question is whether this moral sense is supposed to be tied to particular forms of transgressions, such as harming or helping-hindering others. Most of the research on infant evaluations of others' actions has relied on scenarios involving helping-hindering or fairness, yet the definition of moral sense is not limited to such scenarios [Geraci \& Surian, 2011; Hamlin \& Wynn, 2011; Hamlin et al., 2007; Hamlin, Wynn, Bloom, \& Mahajan, 2011]. The question is then whether the innate moral core is hypothesized to comprise additional moral concerns not yet investigated, such as the prohibition against harming others, or whether the hypothesized moral sense consists of multiple distinct tendencies, only some of which are proposed to be innate.

A second question regarding the nativist definition of a moral sense is whether infants' moral sense is to be applied to the child's own actions or whether it only is activated upon observing the actions of others. According to most views, morality pertains to one's own actions as well as those of others. A person who thinks that he or she is generally permitted to steal, but that no one else is, would have a deficient moral sense by most definitions. Yet, there is currently no evidence that infants are evaluating their own transgressions negatively around or before the first birthday. Sign of negative reactions following one's own transgressions is usually not seen until around the second birthday or later [Barrett, Zahn-Waxler, \& Cole, 1993]. The seemingly late emergence of guilt and shame reactions is not due to the lack of opportunity. Infants engage in a large number of transgressions during the second year of life, and there is an increase in provoked and unprovoked aggressive incidents during the first half of the second year [Dahl, 2014; Dunn, 1988; Hay, 2005; Kuczynski, Kochanska, Radke-Yarrow, \& Girnius-Brown, 1987].

On the surface, the concept of "innateness" seems to have a more obvious definition ("present at birth") than the concept of morality. However, as noted by Tafreshi and her colleagues, the term has been used differently among different researchers endorsing variants of nativist or core knowledge views. The above-mentioned definition by Bloom [2013] requires that the ability not be learned through the extraction of information from the environment for it to be innate; it does not need to be present at birth. Notably, this definition of innateness does not distinguish between types of processes by which children develop knowledge through social experiences. In research on social and moral development, it has been common to distinguish between transmission models and construction models of how children acquire social knowledge [Damon, 1999; Piaget, 1932; Turiel, 1983b]. Transmission refers to children's internalization of norms held by authority figures, whereas construction involves the generation of novel forms of thought through interactions with the environment. It would seem that construction of forms of thought is not just "extraction of information," yet such construction does not fit well with a nativist approach since it involves development through distinct forms of interactions with the world. 
Other researchers talk about core knowledge systems that are proposed to be constant across development [Spelke \& Kinzler, 2007]. Yet others suggest that concepts of innateness should be avoided altogether [Racine, 2013; Spencer, Blumberg, McMurray, Robinson, Samuelson, \& Tomblin, 2009]. Rather than going as far as the latter writers, the purpose of the present discussion is to encourage those who use the concept of innateness to provide a definition of this term along with criteria for deciding whether some property is innate or not.

\section{Attribution of Evaluations and Judgments to Infants}

A main point in the article by Tafreshi and her colleagues is that looking behavior does not license claims about evaluations, judgments, or understandings. They argue looking behavior can have a multitude of different meanings and that it is difficult or impossible to decide empirically what a specific act of looking means: "To ask the question of what it means for an infant to look at an object is to delve into the realm of philosophical inquiry" [Tafreshi et al., this issue]. By this, the authors mean that only an analysis of the term "looking" will tell us whether we can ever infer moral evaluations from looking behavior. The authors argue that "on an everyday usage of concepts, the act of looking in itself cannot tell us what looking means for the infant." In other words, their conceptual analysis leads the authors to conclude that looking can never provide evidence about how an infant is evaluating a social situation.

There is no doubt that looking behavior can reflect different psychological states and serve different functions [Aslin, 2007]. However, researchers are (almost) never left to interpret looking behavior (or other behaviors) in isolation from the context in which it occurs and the other related behaviors exhibited by the individual. On the contrary, it is often possible to set up a context in which infants' looking behavior can be interpreted with a high level of confidence. Two compelling and well-known examples include infant anticipatory looking to a location where an event has previously taken place [Acredolo, 1978], which reflects an anticipation that the event will occur again, and the inverse U-shaped relation between stimulus complexity and infant looking [Kagan, 2008; Kidd, Piantadosi, \& Aslin, 2012], which reflects a tendency to seek out information that is neither too novel nor too familiar.

Ambiguity does arise when there are multiple plausible explanations of infant looking that are equally consistent with the data. One common variant of this situation is when one cannot tell whether infant looking behavior reflects a lower-level perceptual process or a higher-level cognitive process because both explanations are consistent with the data [Aslin, 2000; Haith, 1998]. Criticisms based on lower-level perceptual confounds have in fact been leveled against at least one of the studies by Hamlin and her colleagues [Hamlin et. al, 2007; Scarf, Imuta, Colombo, \& Hayne, 2012; see Hamlin, Wynn, \& Bloom, 2012, for a reply]. Yet, Tafreshi and her colleagues do not concern themselves with possible lower-level explanations for the findings taken as evidence for sociomoral evaluations in infants. Rather, they focus on the discrepancy between "technical uses and everyday aesthetic usage." As already mentioned, I do not see why researchers are necessarily obliged to comply with everyday usage of terms.

Nevertheless, important questions can be raised about the type of evaluations infants are demonstrating via preferential looking and reaching toward "prosocial," "antisocial," or "neutral" puppets. First, it will be remembered that the definition of a mor- 
al sense used by Hamlin [2013] referred to a tendency to see actions or agents as goodbad, right-wrong, and so on. This seems like a reasonable feature of a moral sense, yet it is not one that is required in order to prefer one puppet over another, or even to distribute resources to one puppet rather than another [Hamlin et al., 2011]. Indeed, it is possible that the children do not see anything wrong with what an antisocial puppet is doing - it is just that the child has a more positive evaluation of the prosocial or neutral puppet than the antisocial puppet. For instance, when forced to choose, 26-month-olds and preschoolers (but not 17- or 22-month-olds) tended to help a prosocial human agent rather than an antisocial agent [Dahl, Schuck, \& Campos, 2013; Vaish, Carpenter, \& Tomasello, 2010]. Yet, most children in these studies were still willing to help the antisocial agent when there were no other potential recipients of help.

In contrast to the above preferences or relative evaluations, judging something as wrong is an absolute evaluation that does not involve a comparison of one agent to another. For instance, we do not just put violent criminals at the bottom of the list of people we want to spend time with: We send them to prison. Similarly, preschoolers protest against moral transgressions, and judge them as wrong, by the third or fourth year of life [e.g. Schmidt, Rakoczy, \& Tomasello, 2012; Smetana \& Braeges, 1990]. The current evidence does not reveal whether infant looking and reaching preferences are driven by the kinds of categorical evaluations implied by the above definition of a moral sense.

A separate issue concerns the basis on which the infants form preferences. Like adults, older children distinguish between (1) decisions about who they want to interact with and (2) moral, impartial considerations, for instance about basic rights [Killen \& Stangor, 2001]. In contrast, data on infants' social evaluations so far do not tell us whether infants' preferences simply reflect who they want to interact with or whether these preferences express impartial third-party evaluations. In the first case, infants would be engaging in "friend-and-foe-detection," as suggested by Hamlin [2014]. The results from one study seems particularly consistent with this idea that infants are searching for potential "collaborators" [Hamlin, Mahajan, Liberman, \& Wynn, 2013]. Here, 9and 14-month-olds were found to exhibit preferential reaching toward puppets who hindered a puppet who did not share infants' food preference (as opposed to puppets who helped a puppet who did not share the infants' food preference). In other words, infants appeared to prefer a puppet who was similar to them over a puppet who had done a good deed [see also Kinzler, Dupoux, \& Spelke, 2007]. Alternatively, infants could be evaluating the actions of others without a regard for their own potential cooperation with those being evaluated. This is presumably what preschoolers do when judging about hypothetical scenarios and when distinguishing between personal and moral considerations [Nucci \& Weber, 1995; Smetana \& Braeges, 1990; Tisak, 1993]. Only the latter, impartial third-party judgments, would seem to require a moral sense of right and wrong. Yet, research with infants so far does not provide clear evidence for such impartial judgments, and may even favor the "friend-and-foe-detection" hypothesis.

\section{Developmental Predecessors and Successors}

The argument is sometimes made that a certain skill is present before children could have had any relevant (social) experiences contributing to the development of this skill. For instance, Hamlin and Wynn [2011] stated: "It is unlikely that infants 
have been sufficiently socialized, by three, five, or even nine months of age, to distinguish between the positive and negative intentions of social others to an extent that would explain our results, yet infants take this difference into account when choosing whom to interact with, based on their reaching and looking behavior" (p. 38). Arguing that infant helping emerged without specific social experiences, Warneken and Tomasello [2006] similarly proposed that "[i]nfants 18 months of age are too young to have received much verbal encouragement for helping from parents" (p. 1302). While these claims may well be true, history suggests that it is very difficult to know what kinds of relevant experience organisms have during given periods without studying these experiences directly [Gottlieb, 1997; Spencer et al., 2009]. For instance, a recent investigation of the social context of infant everyday helping found that most infants help in everyday life by early in the second year and that their acts of helping are typically accompanied by encouragement, praise, thanking, and participation from family members [Dahl, 2013, under review]. Without investigating the relation between early experiences and the development of infant preferential looking and reaching, we will not know what role (if any) early experiences play.

It is equally important to study developmental successors of infant preferential looking and reaching following observation of various social scenarios. Most nativist accounts propose that the moral sense argued to be present in infants is a building block for subsequent moral development [Bloom, 2013; Hamlin, 2014]. Yet, this kind of developmental continuity cannot be taken for granted, especially if the nature of the abilities present in infants is qualitatively different from that present later (for instance "friend-and-foe-detection" vs. impartial concepts of right and wrong). The neonatal empathic cry - often taken as a prime example of an innate moral propensity [however, see Campos, Witherington, Anderson, Frankel, Uchiyama, \& BarbuRoth, 2008] - seems to disappear over the course of the first year [Hay, Nash, \& Pedersen, 1981]. Prosocial behavioral responses to distress do not emerge until the second year of life [Hoffman, 2007; Sagi \& Hoffman, 1976]. To my knowledge, only one study has investigated and documented a relation between infant performance on a sociocognitive looking-time task and sociocognitive abilities (performance on a theory of mind task) in preschoolers [Yamaguchi, Kuhlmeier, Wynn, \& vanMarle, 2009]. However, given the time span between the two assessments (3.5 years), even this study reveals little about how early sociocognitive abilities documented in lookingtime studies contribute to subsequent morally relevant abilities.

One key topic - both intriguing and daunting - is how infants' seemingly prosocial and antisocial tendencies become integrated over the course of early development. In addition to whatever skills are documented by the above-described research on preferential reaching and looking, infants' empathic and helpful tendencies become increasingly frequent and flexible during the second year [Dahl, under review; Svetlova, Nichols, \& Brownell, 2010; Warneken, 2013; Warneken \& Tomasello, 2006; Zahn-Waxler, Radke-Yarrow, Wagner, \& Chapman, 1992]. During this same period, there are increases in parent-child conflict and in infant aggressive behaviors [Hay, 2005; Rijt-Plooij \& Plooij, 1993]. Some studies have even found positive correlations between prosocial and aggressive tendencies at these ages, even though these two behavioral tendencies are generally negatively correlated later in childhood [Eisenberg, Fabes, \& Spinrad, 2006; Gill \& Calkins, 2003; Hay, Castle, \& Davies, 2000]. How do these seemingly opposed tendencies become integrated into concerns with welfare, 
rights, and fairness? Does the preferential reaching and looking toward prosocial nonhuman agents translate into similar orientations toward human agents [Dahl et al., 2013]? If so, do they facilitate infants' grasp of their own and others' transgressions? Questions about how early (even prenatal) developments set (or do not set) the stage for subsequent moral development are of major importance, whether one takes a nativist or a constructivist point of view.

This commentary has discussed ambiguities in key concepts in some nativist approaches to early moral development. These ambiguities point to future research questions. Unlike Tafreshi and her colleagues, I believe that empirical research addressing these questions has the potential of resolving theoretical differences. Also unlike Tafreshi and her colleagues, I believe that researchers are free to define their key terms as long as those definitions are made explicit. Once the definitions are made explicit, it may turn out that not all ways of defining terms like "morality," "innate," and "evaluation" are equally conducive to understanding how children think and act. For instance, many researchers have argued for distinguishing between different types of normative concerns, some of which may be called moral (welfare, rights, fairness, and justice), while others may be called conventional [see Turiel, 2014]. Importantly, this view is not primarily based on how most people use the term "morality" but rather on work in moral philosophy along with a large body of empirical research showing that children draw qualitative distinctions between these normative concerns from preschool age, if not before [Turiel, 1983a; for a review, see Smetana, 2013]. When researchers choose other definitions, these choices too would presumably have to be based on close attention to the phenomenon under investigation.

\section{Acknowledgment}

I thank Elliot Turiel for comments on a previous version of the paper.

\section{References}

Acredolo, L.P. (1978). Development of spatial orientation in infancy. Developmental Psychology, 14, 224234.

Allen, J.W.P., \& Bickhard, M.H. (2013). Stepping off the pendulum: Why only an action-based approach can transcend the nativist-empiricist debate. Cognitive Development, 28, 96-133.

Aslin, R.N. (2000). Why take the cog out of infant cognition? Infancy, 1, 463-470.

Aslin, R.N. (2007). What's in a look? Developmental Science, 10, 48-53.

Barrett, K.C., Zahn-Waxler, C., \& Cole, P.M. (1993). Avoiders vs. amenders: Implications for the investigation of guilt and shame during toddlerhood? Cognition \& Emotion, 7, 481-505.

Bloom, P. (2012). Moral nativism and moral psychology. In M. Mikulincer \& P.R. Shaver (Eds.), The social psychology of morality: Exploring the causes of good and evil (pp. 71-89). Washington, D.C.: American Psychological Association.

Bloom, P. (2013). Just babies: The origins of good and evil. New York, NY: Crown.

Campos, J.J., Witherington, D., Anderson, D.I., Frankel, C.I., Uchiyama, I., \& Barbu-Roth, M. (2008). Rediscovering development in infancy. Child Development, 79, 1625-1632.

Dahl, A. (2013). The social context of early helping: Naturalistic investigations. Presented at the Jean Piaget Society, Chicago, IL, United States.

Dahl, A. (2014). Mothers' orientations to infants' moral, prudential, and pragmatic transgressions (unpublished doctoral dissertation). University of California, Berkeley, CA.

Dahl, A. (under review). The developing social context of early helping behavior.

Dahl, A., Schuck, R.K., \& Campos, J.J. (2013). Do young toddlers act on their social preferences? Developmental Psychology, 49, 1964-1970. 
Damon, W. (1999). Moral development. Scientific American, 20, 24-26.

Dunn, J. (1988). The beginnings of social understanding. Oxford, England: Blackwell.

Eisenberg, N., Fabes, R.A., \& Spinrad, T.L. (2006). Prosocial development. In N. Eisenberg, W. Damon, \& R.M. Lerner (Eds.), Handbook of child psychology (pp. 646-718). Hoboken, NJ: John Wiley \& Sons.

Fischer, K.W., \& Bidell, T. (1991). Constraining nativist inferences about cognitive capacities. In S. Carey \& R. Gelman (Eds.), The epigenesis of mind: Essays on biology and cognition (pp. 199-235). Hillsdale, NJ: Lawrence Erlbaum.

Geraci, A., \& Surian, L. (2011). The developmental roots of fairness: infants' reactions to equal and unequal distributions of resources. Developmental Science, 14, 1012-1020.

Gill, K.L., \& Calkins, S.D. (2003). Do aggressive/destructive toddlers lack concern for others? Behavioral and physiological indicators of empathic responding in 2-year-old children. Development and Psychopathology, 15, 55-71.

Gottlieb, G. (1997). Synthesizing nature-nurture: Prenatal roots of instinctive behavior. Mahwah, N.J.: Lawrence Erlbaum.

Gray, K., Young, L., \& Waytz, A. (2012). Mind perception is the essence of morality. Psychological Inqui$r y, 23,101-124$.

Greene, J.D. (2007). The biology of morality: Neuroscientists respond to Killen and Smetana. Human Development. http://www.karger.com/ProdukteDB/Katalogteile/issn/_0018_716X/HDE-Letters-toEditor-10-09-2007.pdf.

Haidt, J. (2008). Morality. Perspectives on Psychological Science, 3, 65-72.

Haith, M.M. (1998). Who put the cog in infant cognition? Is rich interpretation too costly? Infant Behavior and Development, 21, 167-179.

- Hamlin, J.K. (2013). Moral judgment and action in preverbal infants and toddlers: Evidence for an innate moral core. Current Directions in Psychological Science, 22, 186-193.

Hamlin, J.K. (2014). The origins of human morality: Complex socio-moral evaluations by preverbal infants. In J. Decety \& Y. Christen (Eds.), New frontiers in social neuroscience (Vol. 21, pp. 165-188). Cham, Switzerland: Springer International.

Hamlin, J.K., Mahajan, N., Liberman, Z., \& Wynn, K. (2013). Not like me = bad: Infants prefer those who harm dissimilar others. Psychological Science, 24, 589-594.

Hamlin, J.K., \& Wynn, K. (2011). Young infants prefer prosocial to antisocial others. Cognitive Development, 26, 30-39.

- Hamlin, J.K., Wynn, K., \& Bloom, P. (2007). Social evaluation by preverbal infants. Nature, 450, 557-559.

Hamlin, J.K., Wynn, K., \& Bloom, P. (2012). The case for social evaluation in infants. PLoS One, 7. Retrieved from http://www.plosone.org/annotation/listThread.action?root=52853.

Hamlin, J.K., Wynn, K., Bloom, P., \& Mahajan, N. (2011). How infants and toddlers react to antisocial others. Proceedings of the National Academy of Sciences, 108, 19931-19936.

Hay, D.F. (2005). The beginnings of aggression in infancy. In R.E. Tremblay, W.W. Hartup, \& J. Archer (Eds.), Developmental origins of aggression (pp. 107-132). New York, NY: Guilford Press.

Hay, D.F., Castle, J., \& Davies, L. (2000). Toddlers' use of force against familiar peers: A precursor of serious aggression? Child Development, 71, 457-467.

Hay, D.F., Nash, A., \& Pedersen, J. (1981). Responses of six-month-olds to the distress of their peers. Child Development, 52, 1071-1075.

Hoffman, M.L. (2007). The origins of empathic morality in toddlerhood. In C.A. Brownell \& C.B. Kopp (Eds.), Socioemotional development in the toddler years: transitions and transformations (pp. 132148). New York, NY: Guilford Press.

Kagan, J. (2008). In defense of qualitative changes in development. Child Development, 79, 1606-1624.

Kidd, C., Piantadosi, S.T., \& Aslin, R.N. (2012). The Goldilocks effect: Human infants allocate attention to visual sequences that are neither too simple nor too complex. PLoS One, 7, e36399.

Killen, M., \& Stangor, C. (2001). Children's social reasoning about inclusion and exclusion in gender and race peer group contexts. Child Development, 72, 174-186.

Kinzler, K.D., Dupoux, E., \& Spelke, E.S. (2007). The native language of social cognition. Proceedings of the National Academy of Sciences, 104, 12577-12580.

Kochanska, G., \& Aksan, N. (2006). Children's conscience and self-regulation. Journal of Personality, 74, 1587-1618.

Kuczynski, L., Kochanska, G., Radke-Yarrow, M., \& Girnius-Brown, O. (1987). A developmental interpretation of young children's noncompliance. Developmental Psychology, 23, 799-806.

Machado, A., \& Silva, F.J. (2007). Toward a richer view of the scientific method: The role of conceptual analysis. American Psychologist, 62, 671-681.

Nevo, B. (1985). Face validity revisited. Journal of Educational Measurement, 22, 287-293.

Nucci, L.P., \& Weber, E.K. (1995). Social interactions in the home and the development of young children's conceptions of the personal. Child Development, 66, 1438-1452.

Onishi, K.H., \& Baillargeon, R. (2005). Do 15-month-old infants understand false beliefs? Science, 308, 255-258. 
Piaget, J. (1932). The moral judgment of the child. New York, NY: Simon \& Schuster.

Racine, T.P. (2013). How useful are the concepts "innate" and "adaptation" for explaining human development? Human Development, 56, 141-146.

Rijt-Plooij, H.H., \& Plooij, F.X. (1993). Distinct periods of mother-infant conflict in normal development: sources of progress and germs of pathology. Journal of Child Psychology and Psychiatry, 34, 229-245.

Sagi, A., \& Hoffman, M.L. (1976). Empathic distress in the newborn. Developmental Psychology, 12, 175

Scarf, D., Imuta, K., Colombo, M., \& Hayne, H. (2012). Social evaluation or simple association? Simple associations may explain moral reasoning in infants. PLoS One, 7, e42698.

Schmidt, M.F.H., Rakoczy, H., \& Tomasello, M. (2012). Young children enforce social norms selectively depending on the violator's group affiliation. Cognition, 124, 325-333.

Skinner, B.F. (1971). Beyond freedom and dignity (1st ed.). Indianapolis, IN: Hackett.

Smetana, J.G. (2013). Moral development: the social domain theory view. In P.D. Zelazo (Ed.), The Oxford handbook of developmental psychology, vol. 1: Body and mind (pp. 832-864). Oxford, England: Oxford University Press.

Smetana, J.G., \& Braeges, J.L. (1990). The development of toddlers' moral and conventional judgments. Merrill-Palmer Quarterly, 36, 329-346.

Spelke, E.S., \& Kinzler, K.D. (2007). Core knowledge. Developmental Science, 10, 89-96.

Spencer, J.P., Blumberg, M.S., McMurray, B., Robinson, S.R., Samuelson, L.K., \& Tomblin, J.B. (2009). Short arms and talking eggs: Why we should no longer abide the nativist-empiricist debate. Child Development Perspectives, 3, 79-87.

Svetlova, M., Nichols, S.R., \& Brownell, C.A. (2010). Toddlers' prosocial behavior: From instrumental to empathic to altruistic helping. Child Development, 81, 1814-1827.

Tisak, M.S. (1993). Preschool children's judgments of moral and personal events involving physical harm and property damage. Merrill-Palmer Quarterly, 39, 375-390.

Turiel, E. (1983a). Domains and categories in social-cognitive development. In W.F. Overton (Ed.), The relationship between social and cognitive development (pp. 53-90). Hillsdale, NJ: Erlbaum.

Turiel, E. (1983b). The development of social knowledge: Morality and convention. New York, NY: Cambridge University Press.

Turiel, E. (2014). Moral development. In Handbook of child psychology and developmental science (7th ed., Vol. 1). Hoboken, NJ: Wiley.

Vaish, A., Carpenter, M., \& Tomasello, M. (2010). Young children selectively avoid helping people with harmful intentions. Child Development, 81, 1661-1669.

Warneken, F. (2013). Young children proactively remedy unnoticed accidents. Cognition, 126, 101-108.

Warneken, F., \& Tomasello, M. (2006). Altruistic helping in human infants and young chimpanzees. Science, 311, 1301-1303.

Wittgenstein, L. (1953). Philosophical investigations (G.E. Anscombe, Trans.). Oxford, England: Basil Blackwell.

Wynn, K., \& Bloom, P. (2014). The moral baby. In M. Killen \& J.G. Smetana (Eds.), Handbook of moral development (2nd ed., pp. 435-453). New York, NY: Psychology Press.

Yamaguchi, M., Kuhlmeier, V.A., Wynn, K., \& vanMarle, K. (2009). Continuity in social cognition from infancy to childhood. Developmental Science, 12, 746-752.

Zahn-Waxler, C., Radke-Yarrow, M., Wagner, E., \& Chapman, M. (1992). Development of concern for others. Developmental Psychology, 28, 126-136. 